\title{
100 Anos da Química em Portugal sob os Auspícios da SPQ

\author{
Parte II. O nascimento das Sociedades de Química na Europa e a profissionalização \\ da Química em Portugal
}

\author{
SebAStIÃO J. FormosInHO
}

\begin{abstract}
A companha-se o desenvolvimento da química em Portugal desde a edificação do Laboratotrio Chimico na Universidade de Coimbra, no contexto da Reforma Pombalina. Examinam-se as dificuldades com que a Universidade de Coimbra se deparou para ministrar um ensino prático de qualidade. Com a criação do "Laboratorio de Chimico Municipal do Porto" emerge, como figura ímpar do panorama da química portuguesa, Ferreira da Silva, e assiste-se a uma lenta ascensão de uma certa massa crítica de químicos profissionais dedicados, em muito, a análises de águas e de toxicologia forense, o que Ihes conferiu reconhecimento social nestes domínios. Graças à ação de Ferreira da Silva e colaboradores é criada, em 1905, a Revista de Chimica Pura e Applicada, e como resposta à extinção do Laboratorio Municipal do Porto, Ferreira da Silva mobiliza ainda os químicos da país para a criação, em 28 de dezembro de 1911, da Sociedade Chimica Portugueza. Tudo isto revela que as forças motrizes para um desenvolvimento profissional da química portuguesa não estavam localizadas na capital do Reino, mas sim no Porto e ainda, em menor grau, em Coimbra.
\end{abstract}

\section{O NASCIMENTO DAS SOcIEDADES DE Química NA EUROPA}

Uma questão central que foi objeto de consideração em alguns congressos e workshops de história da química foi o processo de "profissionalização" desta ciência, através da emergência de sociedades químicas na Europa. Fruto de tais esforços, veio a lume sob os auspícios da Royal Society of Chemistry, em 2008, uma obra intitulada "Creating Networks in Chemistry. The Founding and Early History of Chemical Societies in Europe", editada por Anita Kildebaek e Soňa Štrbáňová [1]. Quando socialmente se institucionaliza uma disciplina científica, há sempre necessidade de um processo de demarcação entre atividade científica e não-científica. E esta demarcação processa-se nas zonas de fronteira pela atribuição de um conjunto de características selecionadas para os seus praticantes: métodos, corpo de conhecimentos, valores e organização de trabalho. A conquista de territórios, monopolização de atividades e proteção da autoridade intelectual são três características importantes do processo de profissionalização de uma disciplina científica. Mas há que reconhecer igualmente que as fronteiras da ciência padecem de alguma ambiguidade e mostram flexibilidade,

\footnotetext{
Departamento de Química, Universidade de Coimbra, Rua Larga, 3004-535 Coimbra

E-mail: sformosinho@qui.uc.pt
}

pois evoluem no decurso da história, dependendo dos contextos; por vezes apresentam consistências internas, e também são frequentemente fontes de disputa [2].

Nas sociedades modernas, a ciência é, em termos práticos, a maior fonte de desenvolvimento cognitivo, e todo o seu praticante tem de obter, de alguma forma, uma licença por parte da comunidade científica - o ser reconhecido como credível para produzir interpretações a respeito da natureza e dos seus fenómenos. Dado os cientistas acumularem, em abundância, autoridade intelectual, emerge a problemática da partilha de poder: como é que os cientistas podem manter algum controlo sobre os seus recursos materiais e financeiros ou, por outras palavras, como podem conservar a sua autonomia perante os poderes político e industrial? Até porque as reivindicações para uma regulação pública da ciência não decorrem tanto dos conflitos de uma partilha de poder, mas são geralmente provenientes de insatisfações que se verificam na sociedade. Insatisfações perante os resultados tecnológicos alcançados por meio da ciência quando confrontados com anseios sociais, ou por medos que se suscitam na mesma sociedade [2, 3].

Como afirmou Helge Kragh, a Química é indubitavelmente uma ciên- cia europeia [4]. Se em comparação com a Física e a Astronomia, a química foi uma ciência de nascimento tardio como uma ciência moderna e independente, a verdade é que foi no seu seio que se fundou a primeira "sociedade científica" para esta área disciplinar a um nível nacional: a Chemical Society fundada na Grã-Bretanha em 1841 [5]. Confronte-se com a data da fundação da primeira sociedade de química na Alemanha, o país europeu que superou a Inglaterra no desenvolvimento da química a um nível industrial: Deutsche Chemishe Gesellschaft, em 1867.

Mas a Chemical Society foi antecedida pela London Chemical Society que teve uma vida muito curta, 1824 e 1825, e lançou uma revista semanal para o cidadão comum, The Chemist, que só sobreviveu à sociedade que a lançou por cerca de meio ano. No seu corpo dirigente (vice-presidente) encontrava-se um português, António Joaquim Ferreira Marreco (1835-1882). Um dos seus filhos Algernon Freire Marreco foi o primeiro professor de química do "Colégio Armstrong" da Universidade de Newcastle [6]. O presidente da London Chemical Society foi o ocupadíssimo médico G. Birbeck, que se encontrava, ao tempo, no auge da sua fama. No dizer do historiador W. H. Brock, para além de dificuldades financeiras e desacordos entre os seus membros, a sociedade carecia 
de membros competentes no domínio: "The blind were leading the blind. Either through ignorance, or intellectual arrogance London chemists like Brande, Davy, Faraday, Phillips, Prout and Wollaston, failed to rub shoulders with the Society's rude, would-be chemical philosophers» [7]. E a sua revista também fracassou como empreendimento editorial.

«Durante a maior parte do século XIX, a Grã-Bretanha dispunha da maior e da mais dinâmica economia industrial do mundo. O volume da economia britânica no contexto de um vasto Império criou muitas oportunidades de emprego para os químicos. Não causa surpresa que tenha sido a Grã-Bretanha uma das primeiras nações a desenvolver quer uma comunidade de químicos profissionais quer de sociedades de química. Acresce que os "clubes sociais" e as sociedades de autogoverno, quer fossem clubes e sociedades de conhecimento, profissionais, de intervenção social e cívica, sempre desempenharam um papel proeminente na sociedade britânica, nomeadamente entre a classe média. Por alturas da $1^{\text {a }}$ Grande Guerra, os químicos britânicos operavam numa muita densa rede institucional: em 1912, [...] o diretório das colocações disponibilizadas pelas associações profissionais de químicos, o Institute of Chemistry, listava 24 "sociedades e instituições destinadas a promover o avanço da ciência e da tecnologia químicas". A complexidade do mundo social e profissional implica que faz pouco sentido procurar uma demarcação da comunidade química Britânica em termos de uma única organização. [Robin Mackie] apresenta-nos, de facto, três das mais relevantes destas sociedades paralelas: a [já referida ] Chemical Society fundada em 1841, o Institute of Chemistry em 1877, a Society for Chemical Industry, em 1881» [8].

A Chemical Society tinha por objetivo congregar todos os interessados no avanço da química e de áreas afins, na sua vertente científica. A admissão era por eleição entre os seus membros e não requeria por parte dos nomeados qualquer qualificação formal. O seu primeiro presidente foi Thomas Graham, professor no University College. Mas entre 1860 e 1870 começou a ser debatida, entre uma minoria dos membros da Chemical Society, a necessidade de haver uma qualificação formal; o interesse no avanço da química parecia não bastar. $O$ debate foi suscitado por uma alteração da legislação que estabelecia a necessidade de uma certificação de competência química, e o receio de que o título de Fellow of the Chemical Society (FCS) se degradasse pela entrada nos mercados industriais e nos negócios de Fellows com um treino insuficiente. Deste debate resultou a criação do Institute of Chemistry. O seu primeiro presidente foi Edward Frankland, professor da Escola de Minas. A Society for Chemical Industry veio a congregar muitos membros de indústrias químicas instaladas fora de Londres, nomeadamente no Tyneside e no Lancashire. Enquanto a Chemical Society permaneceu uma sociedade erudita de químicos e a sua revista se focalizou na química pura, a revista da Society for Chemical Industry veio a ser uma revista proeminente para a química aplicada [9].

Os anos da fundação das sociedades de química correspondem, em larga medida, ao grau de evolução da ciência química nos diferentes países europeus [10]. Com uma entrada tardia no ensino das ciências experimentais a nível universitário no nosso país, que vem com a Reforma Pombalina de 1772, e sem termos sofrido um significativo processo de industrialização, não causa surpresa que a criação da "Sociedade Chimica Portugueza" surja já tardiamente, em confrontação com os 19 países europeus que Anita Kildebaek Nielsen e Soňa Štrbáňová registam. Os mais tardios são: 1907 Hungria, 1911 Portugal e 1917 Polónia [11].

\section{O Laboratorio Chimico da Universi-} dade de Coimbra e o Ensino Prático DA QUÍMICA

«Os Museus de História Natural, de que fazem parte os Museus Mineralógicos e Geológicos das três Universidades Clássicas Portuguesas, têm origem próxima nos Gabinetes de Curiosidades do Renascimento e do Período Iluminista. Estes Gabinetes que tinham inicialmente por objetivo reunir objetos que pudessem de algum modo causar o espanto dos amigos e visitas dos seus donos (e que incluíam desde objetos de arte até exemplares de animais e plantas exóticos ou mesmo de malformações de embriões de animais domésticos), foram-se tornando progressivamente mais organizados e mais especializados. [...] Mas, enquanto as famílias nobres aderiam de forma bastante entusiástica ao gosto pelo colecionismo, que a partir do Renascimento começou a intensificar-se um pouco por toda a Europa, a Universidade portuguesa assemelhou-se, durante os primeiros séculos da sua existência, ao Mouseion dos antigos gregos, com as suas longas dissertações, mas sem nenhum estudo com componente prática, a não ser no caso da Medicina. As estruturas que eventualmente haveriam de dar origem aos Museus universitários só começariam a surgir no final do século XVII assumindo maior expressão durante o século XVIII. Tal foi o caso da denominada Academia dos Generosos, e de uma outra que abriu em Lisboa, em 1725, dirigida por um inglês, L. Baden, onde se professavam Cursos de Ciências [...]. Nestas academias privilegiava-se o ensino das Ciências com uma forte componente prática, sendo as lições teóricas acompanhadas por atividades experimentais, uma vez que, particularmente no caso da academia de Baden, o equipamento de laboratório era bastante avançado para a época. Para além destas instituições de caráter particular, tinham os padres oratorianos sido encarregados pelo rei D. João $V$ de ensinar disciplinas em que se incluíam a Filosofia e a Física, possuindo uma vasta biblioteca e um Gabinete de Física Experimental [...]. Seria, aliás, no reinado de D. João $\mathrm{V}$ que começaria a divisar-se a evolução na mentalidade dos governantes portugueses que viria a culminar com as reformas levadas a cabo no reinado seguinte (de D. José) por iniciativa do Marquês de Pombal» [12].

No que diz respeito à Química, Portugal usufrui de uma situação relativamente ímpar. O primeiro edifício construído em exclusivo para o ensino da química a nível universitário foi o Laboratorio Chimico em Coimbra. Trata-se do edifício neoclássico português mais importante, em forma de $L$, onde 
o braço mais curto se reconheceu, no restauro do edifício para a instalação do Museu da Ciência, ter aproveitado - Refeitório dos jesuítas, concluído em 1596. O Laboratorio foi construído para o ensino da Química entre 1773 e 1777, durante a reforma da Universidade de Coimbra iniciada pelo Marquês de Pombal, com uma estrutura vocacionada para a prática da química em «ponto grande». Trata-se do primeiro laboratório universitário em Portugal e um raro sobrevivente do século XVIII com a estrutura quase intacta.

«As dificuldades de um impacto da ciência moderna na cultura portuguesa são também de índole social e vieram ao de cimo após o período de florescimento da Reforma Pombalina. O século XIX português foi um clima bem pernicioso para o desenvolvimento do ensino. Não obstante, a Faculdade de Filosofia da Universidade de Coimbra tentou manter-se atenta a alguns ventos que sopravam da Alemanha, da França e da Inglaterra a respeito da necessidade do ensino experimental no domínio da química. Digamos que a Faculdade patenteava alguma confiança na capacidade de poder acompanhar o que de melhor se fazia lá fora. E em química, o grande modelo era a Alemanha. A decadência científica foi-se instalando no país durante o século XIX, mas a partir de meados deste século o "Laboratorio Chymico" procurou recuperar mediante a aquisição de novo equipamento laboratorial, na organização da biblioteca e na ligação a centros estrangeiros, tudo em busca de uma maior exigência. $\mathrm{Na}$ Alemanha pacífica e prestigiada do século XIX, para além de Justus Liebig, houve grandes mestres em química, como Friedrich Wohler, em Göttingen, que atraiu mais de 1200 estudantes americanos e de outros países europeus [13]. Igualmente, Bernhard Tollens, com a sua escola de química agrícola também em Göttingen, merece referência como um dos líderes mais importantes destes "laboratórios universitários menores" [14]. Atraída pelo impacto que o jovem Tollens havia conseguido em Paris, como assistente de Wurtz, com o seu contributo para a síntese do álcool alílico, é perante o novo clima de ensino universitário iniciado por Liebig que a
"Faculdade de Philosophia" da Universidade de Coimbra decide contratar o Dr. Bernhard Tollens "para dirigir os trabalhos práticos do Laboratorio Chimico"» [15]. Em suma, a solução que os professores da Universidade de Coimbra encontraram para "profissionalizar" o ensino prático da química na universidade.

Tollens esteve em Coimbra como «encarregado de trabalhos» cerca de 11 meses, entre 1868 e 1869, tendo depois abandonado esta posição para ocupar uma posição académica na Universidade de Göttingen na Alemanha. Atendamos ao seu extenso relatório enviado de Göttingen e datado de 7 de janeiro de 1873, cerca de quatro anos depois de ter deixado Coimbra. Na ortografia de hoje, escreveu Tollens: «Um domínio muito importante e muito dispendioso é o das coleções e laboratórios da Faculdade de Filosofia. Estes estabelecimentos são para o estudante de Filosofia o que a anatomia e os hospitais são para o médico. É claro que estes estabelecimentos são absolutamente indispensáveis, e com efeito desde muito tempo são objeto de especial cuidado. É principalmente a química a que em nossos dias é a mais exigente, e sumptuosos edifícios testemunham o cuidado dos governos para auxiliar os progressos d'esta ciência. [...] Antes de fazer a descrição dos estabelecimentos notemos que eles apresentam entre outras vantagens para o professor e para os estudantes a de estabelecerem um contacto diário entre eles. Criam-se deste modo relações mais íntimas entre o sábio e o aluno, e o primeiro sabe de um modo seguro o que falta aos conhecimentos do segundo, e modifica as suas lições no sentido de suprir essa falta. [...] Por estas razões se agregam ao professor um ou mais preparadores ou assistentes (Assistent), que lhe preparam as demonstrações práticas das curvas, ou the servem para o auxiliar na instrução prática dos alunos. São os chefes dos laboratórios práticos» [16].

«É a química a que exige mais em relação a estabelecimentos espaçosos. Na maior parte das universidades alemãs existem sumptuosos laboratórios que permitem que um grande número de alunos se ocupem dos trabalhos necessários para adquirir a prática indispensável para empreender investigações teóricas e práticas. [...] Junto à mesa das demonstrações estão as tinas de mercúrio e água; os fornos e chaminés, etc. estão ao alcance do experimentador, e os gases irrespiráveis têm saída pelos condutores que se abrem na chaminé de aspiração. As salas de alunos são espaçosas e bem ventiladas; e em Gotinga, por exemplo, têm 100 lugares para 100 alunos; em Berlim para o mesmo número; em Bona para perto de 130; e assim noutras. [...] Quando uma ciência exige coleções e edifícios próprios, é muito útil que o diretor resida no próprio estabelecimento; e pelo que toca à química é isso indispensável» [16].

Muito destes requisitos vêm-se a encontrar no Laboratorio Chimico da Universidade de Coimbra, mas com menos disponibilidades para o ensino prático de um elevado número de alunos. O que está de acordo com o facto de o Laboratório Chimico ter sido planeado segundo o modelo de um laboratório de química de Viena pelo engenheiro militar Guilherme Elsden. Joaquim dos Santos e Silva, ainda a frequentar os preparatórios do Liceu, serve desde 1 de novembro de 1864 como «ajudante interino do guarda e preparador do Laboratorio Chimico», tarefa que cumpriu até 18 de outubro de 1868. Nos começos do ano letivo 1868-69 chega a Coimbra Tollens, e Santos e Silva teve a concessão especial de trabalhar no seu laboratório e receber instruções deste químico alemão. Como refere Ferreira da Silva, «por tal forma se acentuou a capacidade de [Santos e Silva] e se revelaram as suas aptidões para os trabalhos de laboratório, que alguns professores influentes da Faculdade pensaram em aproveitá-lo para ocupar um dia uma posição regular no laboratório», a de Chefe dos trabalhos práticos do Laboratorio Chimico da Universidade de Coimbra.

Como referido, Tollens esteve em Coimbra durante um ano letivo, tendo rescindido o seu contrato em março de 1870 para ir para Göttingen, como assistente de Wöhler, tendo, decorrido dois meses, obtido a sua habilitation e passado a ocupar a posição de privatdozent. A saída de Tollens 
deixa o Laboratório Químico sem chefe dos trabalhos práticos e as diligências para a sua substituição, apesar de envolver diretamente o Reitor da Universidade, Júlio Máximo de Oliveira Pimentel (Visconde de Vila Maior), foram um pouco tormentosas. Mas a Universidade, perante algumas recusas, acabou por convidar Santos e Silva [17]. Foi inicialmente para Göttingen, e desde outubro de 1871 até agosto de 1872 seguiu cursos de química mineral, química orgânica e química aplicada, ministrados respetivamente por Wöhler, Hübner e Tollens. Depois, seguiu para Bonn para trabalhar com August Kekulé, durante mais um ano letivo, durante o qual realizou investigação original e publicou um artigo científico com a permissão deste eminente químico [18].

Não obstante dispor de um laboratório para os estudos de química, foi limitada a investigação em Química na Universidade de Coimbra durante os finais do século XVIII e mesmo no século XIX, apesar dos esforços de certos químicos, como Thomé Rodrigues Sobral e Vicente Seabra. Este último escreveu um compêndio de química, Elementos de Química, dividido em duas partes; a primeira publicada em 1788, e a segunda dois anos depois. Trata-se de uma obra que ficou na história da química portuguesa como a primeira publicação que no nosso país adotou as ideias de R. Kirwan e de Lavoisier, usando já a nova nomenclatura e a nova linguagem do oxigénio [19]. "Uma linguagem é uma álgebra do pensamento", mas a obra de Seabra teve pouco impacto pois não foi adotada como manual para o ensino da química na Universidade de Coimbra. Se antes da Reforma Pombalina os estudos universitários não implicavam nenhum estudo prático, a não ser no caso da Medicina, com esta reforma as dificuldades não foram de todo ultrapassadas, mesmo no caso da Química.

Nos finais do século XVIII, como refere Amorim da Costa, não havia viabilidade para o funcionamento de um Laboratório Químico em grande [20]. Domingos Vandelli tinha a tarefa impossível de simultaneamente pôr em funcionamento o Jardim Botânico e o Laboratorio Chimico, tendo acabado por se dedicar mais à História Natural do que à Química, sem contudo descurar a formação de discípulos [21]. Criticou-se-lhe o não ter cumprido a tarefa de escrever um manual universitário para os alunos de química. Contudo, apesar de outras dificuldades já apontadas, ter-se-ia apercebido que esta ciência, com Lavoisier, estava a passar por um período de transição; a pior ocasião para escrever qualquer livro de ensino, ainda por cima para um adepto do flogisto como sempre foi.

E o tempo veio-lhe dar razão, pois a química era já ao tempo a ciência de maior progresso. «Berthollet e Fourcroy, considerando os immensos serviços que ella póde prestar á humanidade, diziam com enthusiasmo, filho de uma profunda convicção, que nenhuma sciencia merecia mais o titulo de universal do que a Chimica». Ou ainda em Simões de Carvalho: «É por tanto uma necessidade considerar a química, como farol das ciências, da indústria e da civilização» [22].

Só em 1791, com a jubilação de Vandelli, um dos discípulos, Thomé Rodrigues Sobral, assume a direção do Laboratorio Chimico, com uma dedicação de exclusividade à química. Mas a verdade é que os discípulos químicos de Vandelli já haviam alcançado alguns progressos assinaláveis de uma presença que acompanha de muito perto os marcos dos progressos da química no seu tempo, nomeadamente em estudos para a análise e a síntese da água, que incluem o lançamento de uma "machina aerostatica» cheia com hidrogénio em junho de 1784 [23, 24]. Após os irmãos Montgolfier terem feito subir o seu balão cheio de ar quente em Annonay, próximo de Lyon, em junho de 1783, o professor de física Jacques Charles fez subir em Paris um balão cheio de hidrogénio em agosto do mesmo ano [25].

Já sob a direção de Rodrigues Sobral, tem lugar no Chimico o fabrico da pólvora para combater as tropas napoleónicas e as ações de química sanitária para combater o contágio da epidemia que se havia declarado em Coimbra em agosto de 1809.

«Apesar das condições favoráveis criadas pela reforma da Universidade de Coimbra (1772) e das contribuições deste químico [Vicente Seabra], o facto é que em Portugal não se gerou uma comunidade de químicos capazes de produzir investigações originais e de competir no contexto internacional da época» [26].

As dificuldades para um ensino prático de química parecerem ter permanecido quando se dá voz ao Diretor do Laboratorio Chimico Miguel Leite Ferreira Leão, no seu relatório de 5 de maio de 1870: "Os diretores deste estabelecimento têm lutado com graves dificuldades, para desenvolver o ensino prático, em harmonia com a índole da química moderna. A pequena dotação annual, a falta de demonstradores e substitutos privativos d'esta sciencia e de outros empregados technicos e muitas outras causas têm concorrido para mallograr os esforços que se têm feito para conseguir aquele fim. [...] Ha mesmo uma classe de alumnos, os que se destinam ao estudo da pharmacia, que segundo a legislação academica não têm no laboratorio outro ensino que não seja meramente practico, e que pelos Estatutos é mandado fazer pelo guarda; alem d'isto faço eu mesmo na aula sobre a mesa todas as preparações que por sua natureza a isso melhor se prestam, e podem ser observadas por todo o curso, bem como todas as reações caracteristicas, quer dos acidos, quer das bases» [27].

Uma conclusão emerge: não obstante as dificuldades existentes, os alunos de Farmácia tinham um ensino prático de química muito mais intenso do que os outros alunos, mesmo os de «Filosofia Natural». Tal não significa que não tenha havido investigação com algum relevo nacional, mas a emergência de profissionais de química dá-se através da Farmácia.

António Leonardo apresenta na sua dissertação de doutoramento [28] uma compilação dos artigos de química publicados n' $O$ Instituto entre 1852 e 1952 (Tabela 1). Trata-se da revista científica do "Instituto de Coimbra", que foi a sociedade científica e literária nascida, em 1852, no seio da Universidade de Coimbra. 
Tabela 1 - Compilação dos artigos de química publicados n' O Instituto entre 1852 e 1952 [28]

\begin{tabular}{|l|c|c|}
\hline \multicolumn{1}{|c|}{ Temas de química } & Artigos & $\begin{array}{c}\text { Fração } \\
(\%)\end{array}$ \\
\hline Analítica & 26 & 29,5 \\
\hline Forense & 19 & 21,6 \\
\hline Orgânica e Bioquímica & 19 & 21,6 \\
\hline Industria e Metalurgia & 14 & 15,9 \\
\hline $\begin{array}{l}\text { Química-Física e } \\
\text { Inorgânica }\end{array}$ & 10 & 11,4 \\
\hline
\end{tabular}

Como se infere dos dados coligidos, um pouco mais de metade dos temas tratados pelos membros do Instituto de Coimbra em Química diz respeito a análise químicas, em larga medida de águas e de toxicologia. Este panorama traduz bem o que se passava no país e vai-se refletir nos modos de profissionalização da química portuguesa. Como bem enfatiza o autor citado, «o reconhecimento social desta área da química [análise química de águas] foi obtido graças a crescentes preocupações com a higiene e a saúde públicas, a rentabilização de processos agrícolas e industriais, a investigação forense e a hidrologia, entendida como o estudo das diferentes espécies de águas e das suas propriedades, assim como a respetiva distribuição geográfica. Em particular, a questão da salubridade da água para consumo humano desencadeou numerosos estudos sobre águas de fontes, rios, nascentes e lagos. A classificação destas diferentes águas foi determinante não só para a seleção de fontes para o abastecimento público, mas também para a valorização de águas com características benéficas para a saúde» [29]. Para ainda, citando Acciaoli [30], acrescentar: «O ato solene da iniciação de uma água mineral, realiza-se pela Química. É ela que dá foros de nobreza a uma nascente» [31]. «Em 1892 iniciou-se um novo ciclo no tocante às águas minerais portuguesas. Finalmente, o governo regulamentou toda esta atividade, o que levou os agentes que comercializavam este produto a solicitar novas análises químicas, preferindo os analistas mais conceituados. O nome do autor da análise tornou-se uma garantia das virtudes publicitadas, autenticando o valor de uma água mineral. Três nomes se destacaram no número de análises e na fama científica que granjearam:
Santos e Silva, Ferreira da Silva e Lepierre» [32].

A exposição que a Fundação Luso inaugurou em 22 de junho de 2011, "Luso: água puríssima - Charles Lepierre", é uma excelente materialização desta perspetiva de Luís de Meneses Acciaiuoli, pois «a exposição centra-se na vida de Charles Lepierre, que foi um precursor em Portugal na área de investigação científica e que contribuiu para o desenvolvimento da aplicação química aos recursos naturais, medicina e indústria» [33].

\section{Os Laboratórios de Química de Lis-} boa e do Porto e a ProfissionalizaÇão dos Químicos Portugueses

Em 1864, o centro demográfico de Portugal encontrava-se ligeiramente a leste de S. Miguel de Poiares [34]. Depois move-se para sul e para oeste. Precisamente, no início do século $X X$, encontrava-se muito próximo da vila da Lousã, e em 2001 no concelho de Soure, muito perto da fronteira entre o distrito de Coimbra e o de Leiria. Um tal centro demográfico parece ser quase o centro de um "halter". Duas grandes massas demográficas, uma concentrada em Lisboa e cercanias, alcançando já os $35 \%$ do total da população nacional, e outra a norte, mais dispersa, no Porto e no Minho. O Centro do país é menos populoso, e o Algarve tem uma demografia própria.

Contudo, nos começos do século XX, a Revista de Chimica Pura e Applicada e as forças motrizes que levaram à criação da Sociedade Chimica Portugueza estão localizadas na cidade do Porto, e não em Lisboa, a capital do Reino, como bem enfatiza Vanda Leitão et al. [35]. Ao tempo, a cidade do Porto congregava ao seu redor uma mais dinâmica atividade comercial, agrícola e industrial.

Em 1837, fruto das reformas do ensino introduzidas por Passos Manuel, foram criadas a Escola Politécnica de Lisboa e a Academia Politécnica do Porto. Ambas vieram a ser dotadas de laboratórios químicos no século XIX em Lisboa e, já em inícios do século XX (1915), no Porto, que merecem destaque e dão alguma expressão à importância que esta disciplina vai ter futuramente no país. Ao laboratório da Universidade do Porto, em 1922, foi atribuído muito justamente o nome "Laboratório Ferreira da Silva".

Em Lisboa, nomeadamente entre 1860 e 1890, houve investigação relevante em química orgânica graças a Agostinho Lourenço, António Augusto d'Aguiar e aos seus coautores germanófonos que permaneceram durante alguns anos no nosso país. Aguiar e Lautemann estudaram a nitração do naftaleno seguida da redução dos dois produtos isolados às duas naftalenodiaminas isoméricas correspondentes, atualmente designadas 1,5 e 1,8-diaminonaftaleno. Merece especial destaque Aguiar, que foi dos primeiros a aventurar-se no estudo da isomeria nos naftalenos dissubstituídos, muito mais difícil do que os vários isómeros de benzenos dissubstituídos e dos antracenos substituídos, ao tempo já conhecidos [36]. Todavia, não houve sucesso na passagem de testemunho para as gerações seguintes e uma química com maior dinamismo vai emergir bem mais a norte.

No Porto, as atividades de química surgem com notoriedade com a tomada de posse de António Joaquim Ferreira da Silva no lugar de lente de Chimica na Academia Polytechnica, em 1877. «Em 1888, iniciam-se, no Laboratorio Municipal, os estudos sobre vinhos (composição elementar, falsificações, etc.), estudos esses que se prolongaram até 1904, muito embora tivessem sido extintos, em 1902, os serviços de análises químicas no Laboratorio Municipal» [38]. E durante cerca de 25 anos este Laboratório Municipal desempenhou um papel de defesa do consumidor no combate à fraude, com métodos analíticos de igual qualidade a laboratórios franceses de referência. Criaram-se assim novas necessidades e meios de financiamento, provenientes de análises de vinho, leite, águas minerais, óleos, bem como de ligações a higiene e toxicologia. Como referem Leitão et al., o Laboratorio Municipal do Porto funcionou como um «centro de propaganda científica» para usos da química [35].

«Em 1881, por proposta do Presidente da Câmara Municipal do Porto, Con- 
selheiro Dr. J. A. Correia de Barros, foi deliberado criar-se um Laboratorio Chimico Municipal, tendo Ferreira da Silva sido convidado a encarregar-se da sua instalação» [37]. A "Sociedade Chimica Portugueza” surge já como fruto da criação do "Laboratorio de Chimico Municipal do Porto", que foi aberto ao público em 1884, e da vinda a lume da "Revista de Chimica Pura e Applicada", em 1905, sob a ação de Ferreira da Silva e dos seus colaboradores Alberto d'Aguiar e José Pereira Salgado (Figura 1). A redação e administração da revista é na Rua do Laranjal, 41, morada do Laboratório Municipal, facto que desagradou à Câmara Municipal do Porto. O facto da Sociedade ter sido fundada já após a criação de uma revista nacional de química contrasta com o que se verificou em outros países europeus [35].

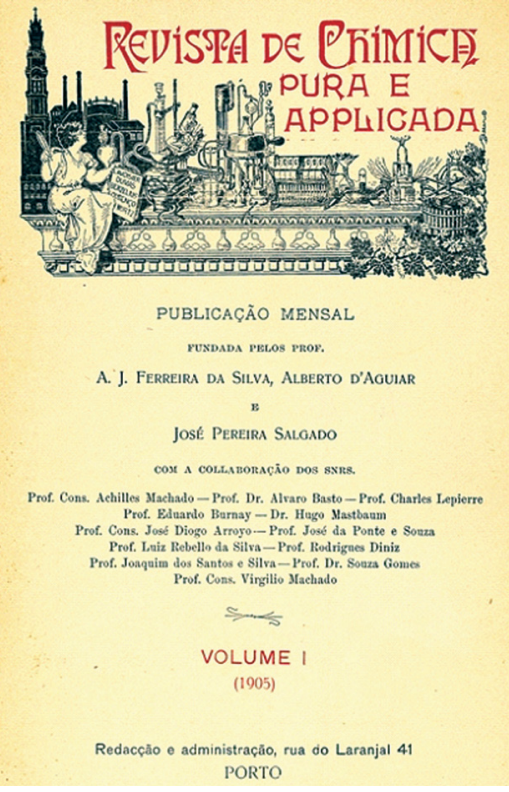

Figura 1 - Capa do 1o volume da Revista de Chimica Pura e Applicada, fundada por Ferreira da Silva, Alberto d'Aguiar e Pereira Salgado, tirada a lume em 1905, com a morada de Rua do Laranjal 41, Porto

O primeiro número da "Revista de Chimica Pura e Applicada" surge com a data de janeiro de 1905 e do programa apresentado realçamos: «A publicação periodica e regular d'uma revista portugueza de chimica tornou-se uma necessidade urgente. A remodelação que entre nós sofreram ultimamente os estudos de chimica nos nossos estabelecimentos de ensino superior, a creação das novas cadeiras de chimica pharmaceutica, de chimica bromatologica e toxicologica nas Escolas de Pharmacia, a instituição dos cursos de chimica sanitaria pelas recentes reformas do ensino da hygiene, a organisação e melhoramento dos laboratorios medicos junto das Escolas medicas de Lisboa, Coimbra e Porto, justificam bem tal necessidade.

Mas ha mais: possuimos laboratorios agricolas, de hygiene, clinicos e technicos, uns mantidos pelo estado, outros pelas municipalidades, e, finalmente, outros por particulares; existe organisado um pequeno nucleo de industrias chimicas, representadas por fabricas de sulfureto de carbono, acidos sulfurico e chlorhydrico, velas estearicas, sabões, oleina, adubos chimicos, etc., e, acima de tudo, temos na fertilidade do nosso solo agrícola um caudal de applicações e estudos chimicos, que aproveitam muito directamente a riqueza e prosperidade do paiz.

Já ha chimica sufficiente para que nos abalancemos a esta empreza, procurando recolher os trabalhos sahidos d'estas varias origens, e que difficilmente, e só por generosidade, encontram acolhida em publicações diversas - medicas, pharmaceuticas, agricolas, etc. [...] A nossa missão será, pois, archivar o que já produz nos nossos laboratorios, orientar os que trabalham nos progressos incessantemente realisados e de que dão conta as publicações congeneres estrangeiras, publicar artigos de explanação scientifica doutrinaria ou experimental, que possam ser d'utilidade aos alumnos que frequentam as nossas cadeiras de chimica geral e especial, e aos que desejam ficar ao corrente dos progressos mais notaveis das sciencias chimicas.

A litteratura e historia da sciencia chimica honrarão a nossa revista; e, para isso, escolheremos de preferencia os assumptos versados pelos nossos homens de sciencia mais eminentes, tornando assim conhecidas algumas preciosas joias litterarias; e, quando a opportunidade se nos deparar, procuraremos tambem traçar a obra dos nossos mais notaveis chimicos. Por esta dupla fórma prestaremos á sua maioria o nosso preito de veneração. As questoes de chimica pura terão aqui acolhimento e cabimento; é, porém, de crer que, por conveniencia de meio, tenhamos de dar preferencia a assumptos de chimica applicada à hygiene, á agricultura, á medicina, á pharmacia, á medicina legal, etc.» [42].

Com efeito, com a criação da disciplina de "química farmacêutica" em moldes científicos nos currículos do ensino superior, a reforma legislativa de Hintze Ribeiro havia concedido maior autonomia a farmacêuticos em relação aos médicos, no campo das análises. Como refere o nosso saudoso colega Prof. João Cabral, «Ferreira da Silva foi praticamente um autodidacta em Química Analítica. É neste período, 1877 a 1884, que ele dedica o melhor do seu esforço na aquisição dos conhecimentos e das técnicas experimentais em Química Analítica, o que, no futuro, Ihe grangearia bem merecida fama». Os seus sucessos de maior impacto internacional foram sobre estudos analíticos de alcalóides: duas reações novas para a identificação da cocaína e da eserina e um reagente para alcalóides, o "reagente Ferreira da Silva" [37].

Ferreira da Silva obteve o grau de Bacharel em Filosofia Natural pela Universidade de Coimbra, em 11 de junho de 1876. A necessidade de Ferreira da Silva ter de ser um autodidata em química analítica é também, de algum modo, reflexo de um ensino experimental débil na Universidade de Coimbra para os alunos de "Filosofia Natural". Mas é também expressão de ser pequena a massa de profissionais com práticas de química em Portugal, quer no campo da medicina e da farmácia, quer na indústria alimentar. Com efeito, o número de membros da Sociedade de Chimica Portugueza em 1912, pouco após a sua fundação, era de 76 , para subir para praticamente o dobro, 146, em 1915; em 1928 o número de membros alcançou o valor de 214 [35]. Mas neste último ano a Sociedade, dada a carência de uma massa crítica, já se havia convertido, em 1926, na Sociedade Portuguesa de Química e de Física.

No contexto nacional nunca se colocou a necessidade de uma demarcação profissional dos praticantes da química como noutros países europeus. Igualmente, como reflexo de uma investigação ainda incipiente, realizada a nível individual, raríssimos são os artigos na Revista de Chimica Pura 
e Applicada, mesmo já sob os auspícios da Sociedade de Chimica Portugueza, com mais do que um autor.

Em 25 de Abril de 1907 foi proposta a extinção do Laboratorio Chimico $\mathrm{Mu}$ nicipal do Porto (LQMP), que Ferreira da Silva procurou impedir. Análises de vinhos e de outros alimentos, de minérios ou de matérias para a indústria, eram realizadas em Paris ou noutros laboratórios europeus antes da criação deste laboratório químico municipal. Em editorial publicado na Revista de Chimica Pura e Applicada, em janeiro de 1909, lastimando a extinção do LQMP, Ferreira da Silva afirma seguidamente: «E n'esta situação, que justifica o apregoado divorcio entre o pensar do governo e o dos seus governantes, vamos assistindo indifferentes aos progressos incessantes da sciencia, sem attender a que, pela penuria verdadeiramente vergonhosa das nossas instituições laboratoriaes, nem os nossos productos conhecemos, deixando ao estrangeiro o interesse de esclarecer muitos pontos da sua curiosa composição. É assim que os vinhos do Porto foram analysados por Bertholet, Bossingault, em França; por Fresenius, na Allemanha; ..., etc.». E novamente, após 25 anos de bons serviços à região, se regressou ao passado, dada a onda de obscurantismo das autoridades municipais invocando gastos excessivos.

É na sequência da extinção do LQMP que Ferreira da Silva vem propor a criação de uma "sociedade científica" de química, como um novo modo de fomentar a investigação desta ciência em Portugal e também combater, entre nós, o hiato entre a química pura e aplicada [35].

Em 28 de dezembro de 1911, os membros fundadores da "Sociedade Chimica Portugueza" reuniram-se no Laboratório de Química da Escola Politécnica de Lisboa. Para além de Ferreira da Silva, estiveram presentes Álvaro Basto, José Pereira Salgado, Carl von Bonhorst (professor na Escola Marquês de Pombal), César Lima Alves (professor no Instituto Superior de Agricultura), Armando Artur de Seabra, Artur Cardoso Pereira (professor da Faculdade de Medicina) e Hugo Mastbaum, tendo ficado incumbidos

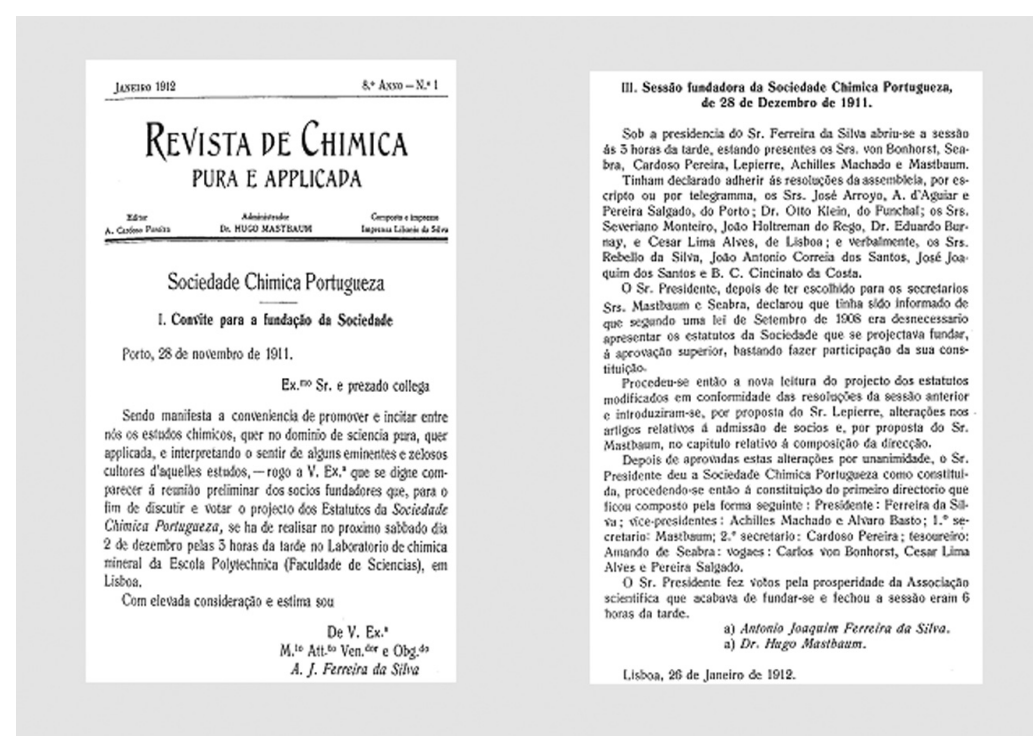

Figura 2 - Convite para a fundação da Sociedade Chimica Portugueza e ata da fundação

de fazer o lançamento da Sociedade (Figura 2).

\section{AgradeCIMENTOS}

Agradeço ao Prof. Augusto Correia Cardoso as valiosas discussões sobre os temas de história da química abordados neste trabalho e a disponibilização de alguns documentos, bem como agradeço o apoio financeiro da Fundação para a Ciência e a Tecnologia.

\section{REFERÊNCIAS}

[1] A.K. Nielsen e S. Štrbáňová (ed.), Creating Networks in Chemistry. The Founding and Early History of Chemical Societies in Europe, RSCPublishing, Cambridge, 2008.

[2] T. Gieryn, American Sociological Review, 48 (1983) 781-795.

[3] J. Calado, Haja Luz! Uma história da química através de tudo, IST Press, Lisboa, (2011) , p. 54, 162, 163, 269 , 302, 320.

[4] D. Knigth, H. Kragh (eds.), The Making of the Chemist: The Social History of Chemistry in Europe, 1789-1914, Cambridge University Press, 1998.

[5] Kildebaek, Štrbáňová, ob. cit., p. 329.

[6] M.F. Camões, Química, Boletim $S P Q, 120$ (2011) 55-56.

[7] W.H.Brock,Ambix, 14(1967)133-139.

[8] R. Mackie, "Great Britain: Chemical Societies and the demarcation of the British Chemical Community, 1870-1914", in Creating Networks in Chemistry, RSCPublishing, Cambridge (2008) 139-160.

[9] Id., pp. 140-143.
[10] A.K. Nielsen e S. Štrbáňová, "Creating Networks in Chemistry - some lessons learned", in Creating Networks in Chemistry, RSCPublishing, Cambridge (2008) 330.

[11] Id., Tabela 15.1, p. 330.

[12] Maria Fernanda Gomes, "Os Museus Mineralógicos e Geológicos de três Universidades Portuguesas (Lisboa, Coimbra e Porto)", em Colecções e Museus de Geologia: missão e gestão, J. M. Brandão, Pedro M. Callapez, Octávio Mateus e Paulo Castro (eds.), Museu Mineralógico e Geológico da Universidade de Coimbra e Centro de Estudos de História e Filosofia da Ciência, Figueira da Foz (2010) 69-74.

[13] H. S. van Klooster, "Friedrich Wöhler and his american pupils", J. Chem. Educ., 21 (1944) 158.

[14] C. A. Browne, "Bernhard Tollens (1841-1918) and some american students of his school of Agricultural Chemistry", J. Chem. Educ., 19, 253 (1942).

[15] S. Formosinho, Nos Bastidores da Ciência. 20 Anos Depois, Imprensa da Universidade de Coimbra, Coimbra (2007) 90, 91.

[16] B. Tollens, "Bosquejo ou exposição sumária da organização das Faculdades de Filosofia nas Universidade de Alemanha", O Instituto, 20, (1875) 49-56, 100-105, 145-151, 193-198.

[17] A.C. Cardoso, B.J. Herold, S.J. Formosinho, "Joaquim dos Santos e Silva: um pioneiro português da química moderna", Actas do Congresso Luso-Brasileiro de História das Ciências, Carlos Fiolhais, Car- 
lota Simões, Décio Martins (coords.), Universidade de Coimbra, 26 a 29 de outubro de 2011, pp. 279-296.

[18] A.J. Ferreira da Silva, "Joaquim dos Santos Silva. Necrologia”, Rev. de Chim. Pura e Apl., $2^{\circ}$ ano, ${ }^{\circ} 4$ (1906) 117.

[19] A.M. Alfonso-Goldfarb, J.L. Goldfarb, M. Ferraz, "O papel das fontes para o estudo das ciências portuguesa e brasileira", Actas do Congresso Luso-Brasileiro de História das Ciências, pp. 1417-1431.

[20] A. M. Amorim da Costa, Primórdios da Ciência Química em Portugal, Biblioteca Breve, vol. 92, Instituto de Cultura e Língua Portuguesa, Lisboa, 1984, 40-45.

[21] S. Formosinho, "A química em Domingos Vandelli: uma arte ou uma ciência?", em Gabinete Transnatural de Domingos Vandelli, Paulo Bernaschina (ed.), Artez (2008) 149-167.

[22] J.A. Simões de Carvalho, Lições de Philosophia Chimica, Imprensa da Universidade, $2^{\mathrm{a}}$ ed., Coimbra (1859) 13, 17.

[23] J.S. Redinha, Bosquejo Histórico da Química na Universidade de Coim- bra", Rev. Port. Quim., 29 (1987) 140-150.

[24] Amorim da Costa, Primórdios da Ciência Química em Portugal, 102-105.

[25] J. Calado, ob. cit. , 246.

[26] António Amorim da Costa, Vicente Coelho de Seabra Silva Telles (c.1764-1804), in http://www.spq.pt/ docs/Biografias/Vicente $\% 20$ Coelho\%20de\%20Seabra\%20\%20port. pdf (acedido 22-05-2011).

[27] J.A. Simões de Carvalho, Memória Histórica da Faculdade de Philosophia, Imprensa da Universidade, Coimbra (1872) 180, 181, 187.

[28] A.J.F. Leonardo, "O Instituto de Coimbra e a evolução da Física e da Química em Portugal de 1852a 1952", dissertação de doutoramento, Universidade de Coimbra, 2011, p. 180.

[29] Id., p. 208.

[30] L.M. Acciaiuoli, História da Química na Hidrologia Portuguesa, Academia das Ciências de Lisboa, 1949, p. 3.

[31] Leonardo, ob. cit., p. 212.

[32] Id., p. 236.

[33] Em http://www.sociedadeagualuso. pt/default.asp?s=54 (acedido em 2406-2011).
[34] J.F. Queiró, "A Demanda do Centro de Portugal", Gazeta de Matemática, 157 (2009) 7-12.

[35] V. Leitão, A. Carneiro e A. Simões, "Portugal: Tackling a Complex Chemical Equation: The Portuguese Society of Chemistry, 1911-1926", in A.K. Nielsen e S. Štrbáňová (ed.), Creating Networks in Chemistry. The Founding and Early History of Chemical Societies in Europe, RSCPublishing, Cambridge (2008) 257-280.

[36] B.J. Herold e A. Carneiro, "Portuguese organic chemists in the 19th century. The failure to develop a school in Portugal in spite of international links", in Proceeedings of the $4^{\text {th }}$ International Conference on History of Chemistry, Communication in Chemistry in Europe across Borders and across Generations, É. Vámos (ed.), Budapest, vol. 1, (2005) 25-48.

[37] João O. Cabral, "Ferreira da Silva e a Química Analítica no Porto", Colóquio/Ciências, Fundação Calouste Gulbenkian, 22 (1998) 71-86.

[38] Revista de Chimica Pura e Applicada, $1^{\circ}$ ano (1905) $1,2$.

\section{Atualdidae Científica}

\section{Membranas Porosas de Grafeno na PROdução de COMBustívels limpos}

Desde as primeiras evidências da existência do óxido de grafite em 1859, pelo químico britânico Benjamin Collins Brodie, até às pesquisas produzidas pelo vencedor do prémio Nobel da Física em 2010, o holandês nascido na Rússia Andre Geim, que o grafeno, um composto alotrópico de carbono de estrutura planar com empacotamento em rede cristalina (uma monocamada de grafite), conquistou um espaço na física e química atuais, nomeadamente no que respeita às suas múltiplas aplicações nas indústrias da eletrónica e nanotecnologia. Até recentemente, uma das propriedades conhecidas do grafeno era a sua impermeabilidade a líquidos e gases, devido à sua estrutura em rede hexagonal densamente povoada por nuvens eletrónicas.

Agora, o mesmo Andre Geim, colegas da Universidade de Manchester (Reino Unido) e ainda cientistas da Universidade de Ciência e Tecnologia da China (Anhui, China), desenvolveram uma membrana de óxido de grafeno que é cerca de 10 mil milhões de vezes mais permeável à água do que ao hélio. As membranas sintetizadas de óxido de grafeno, de aparência similar ao nácar (material que reveste algumas conchas, também designado por madrepérola), demonstraram impermeabilidade aos gases e à maior parte dos líquidos (etanol, hexano e propanol, por exemplo), mas mostraram-se altamente permeáveis à água. Esta descoberta permite antecipar um conjunto de aplicações, não só em processos separativos, mas principalmente na possibilidade (ainda teórica) de separação do hidrogénio de líquidos e misturas gasosas para a produção de combustíveis.

(adaptado de http://www.rsc.org/chemistryworld/News/2012/January/graphene-oxide-membrane.asp)

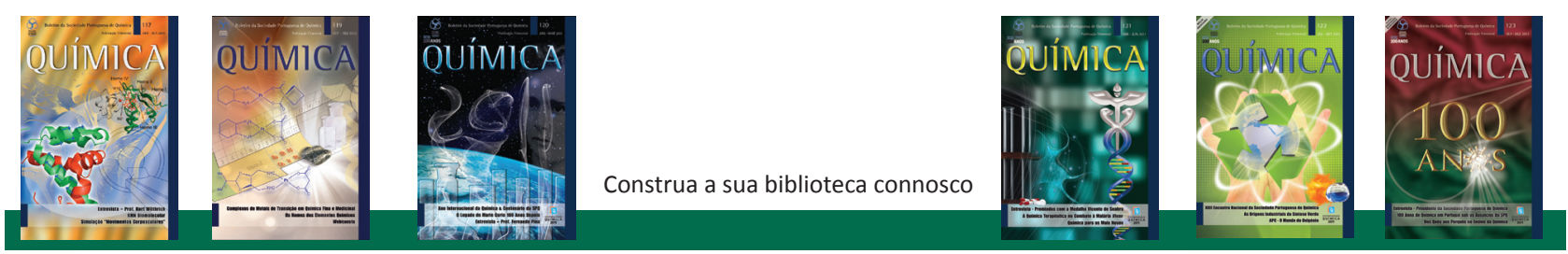

